\title{
Comparison of intercanine width in between Angle class II division 1 and division 2 malocclusions
}

\author{
Bebby Putri*, Isnaniah Malik*, N.R. Yuliawati Zenab* \\ *Department of Orthodontics, Faculty of Dentistry Universitas Padjadjaran, Indonesia
}

\begin{abstract}
Introduction: Dental arch width measurement is needed to determine diagnoses and orthodontic treatment planning of Angle Class II division 1 and Class II division 2 malocclusions that have narrow maxillary dental arch generally. Dental arch width in this study was measured by maxillary and mandibular intercanine width. This study aimed to compare the differences of intercanine width between Angle Class II division 1 and Class II division 2 malocclusions. Methods: Descriptive comparative research with total samples of 67 study models, consisted of 34 Class II division 1 cases and 33 Class II division 2 cases. The minimum age of the samples chosen was 13 years old with no history of orthodontic treatment. A non probability consecutive sampling technique was used. Results: Study results showed the avarage maxillary and mandibular intercanine width of Class II division 1 were $33.99 \mathrm{~mm}$ and $26.33 \mathrm{~mm}$. Average maxillary and mandibular intercanine width of Class II division 2 were $34.77 \mathrm{~mm}$ and $25.37 \mathrm{~mm}$. T-test analysis showed no statistical significant differences in the intercanine width between Angle Class II Division 1 and Class II Division 2 malocclusions. Conclusions: There was no differences in intercanine width in between Angle class II division 1 and division 2 malocclusions.
\end{abstract}

Keywords: Intercanine width, Angle Class II, malocclusion

\section{INTRODUCTION}

Malocclusion is one problem in dentistry that has effect on oral condition and is able to cause problems in mastication, articulation, and arch development. ${ }^{1}$ Malocclusion in permanent dentition is caused by malocclusion in primary dentition. Kaur et al. reported a high prevalence of maloclussion $(87.79 \%$ ) among Indian adolescents aged 13-17.' Based on another studies, the prevalence of maloclussion among Libyan adolescents aged $12-17$ is $95.6 \%$. The prevalence of maloclussion in Indonesia in 2006 was $89 \% .^{2}$ Thus, early management is important to identify the influencing factors of malocclusion in this period and to plan some preventive treatment to decrease the severity and lower the prevalence of malocclusion in the future. ${ }^{1}$

Malocclusions can be categorized using some methods. ${ }^{3}$ Angle's classification is one of the method used to diagnose dental malocclussion based on the relation of the mandibular permanent first molar to the maxillary permanent first molar. ${ }^{4}$ Angle's classification of malocclusion is the most widely used by orthodontists because of its simplicity and practicality. ${ }^{5}$

Angle's classification divided dental malocclusions into 3 Classes, that is Class I, II and III 
malocclusions. This study will explain more about Angle Class II malocclusion which has been categorized into Class II division 1 and Class II division 2 malocclusions. ${ }^{6}$ Angle class II malocclussion is presented with distal relationship of lower teeth to upper teeth and is classified as Class II division 1 and class II division 2 based on the inclination of the incisors of the maxilla. ${ }^{6,7}$ The Class II division 1 malocclusion has the characteristic ' $\mathrm{V}$ ' dental arch form in the maxilla, while the Class II division on 2 malocclusion has the ' $U$ ' form. ${ }^{4}$

Researchers recommend early detection of all classes of malocclusions for treatment options in the correction of dental alignment and dental arches width. In orthodontic field, the intercanine width of the maxilla and the mandible are used as tools to measure the dental arch width. Dental arch differs between each individual because a dental arch is influenced by the environment, nutrition, genetic, race, and sex. ${ }^{8}$ Dental arch width is known as the width of the intercanine of the maxilla and the mandible.

Based on the literature, the maxillary intercanine width is larger than the mandibular intercanine width and commonly, the intercanine width of the male is larger than the female. ${ }^{9}$ Muthaq et al. ${ }^{10}$ have reported that for the average of intercanine width of class II division 2 malocclusion there are no significant differences with Class I, II division 1, and III malocclusions. Moreover, the result from a study by Patel et al. has showed that the average intercanine width of class II division 2 malocclusion is larger than class II division $1 .{ }^{8}$ Therefore, the evaluation of intercanine width is important for proper diagnosis and treatment planning of any orthodontics case as it will affect the availability of spaces, esthetics, and stability of the dentition.

The objectives of this study was to determined the comparison of intercanine width between Angle Class II division 1 and Class II division 2 malocclusions in Orthodontics Department Dental Hospital Universitas Padjadjaran (RSGM Unpad).

\section{METHODS}

The total sample of this comparative research were 67 study models, consisted of 34 models of Class II division 1 and 33 models of Class II division
2 in the Orthodontic Department of Dental Hospital Universitas Padjadjaran. The minimum age of the subjects chosen for this study was 16 years based on the completion of the root of the canine. All subjects selected were patients' study models with no history of orthodontic treatment. A non probability consecutive sampling technique was used.

The inclusion criterias in this research were: the presence of all permanent teeth, from right first molar to left first molar; the roots of all these teeth were already complete (from right first molar to the left first molar) and the study models were in good conditions. The exclusion criterias were: patients/study models with missing teeth, attrition in the occlusal surface of the canines; teeth with large caries and big restorations (these conditions could affect the mesiodistal measurements).

A digital calliper measuring within $0.01 \mathrm{~mm}$ is used in this study to measure the intercanine width of the maxillary and mandibular study models. Intercanine widths were measured on the study models (Patel et al. ${ }^{8}$ ): the cups tips of left and the right canines of the maxilla and the mandible were marked with a mechanic pencil. The width of the intercanine was measured by connecting the marked cups tips with the tips of the digital calliper. Then the result of the intercanine width shown at the digital calliper was recorded.

All the data collected were tabulated according to groups and subjected to appropriate statistical analysis. The statistical methods were comparative hypothesis test averaged two samples using independent $\mathrm{t}$-test formula. The hypothesis in this study were:

$\mathrm{H}_{0}=$ there were no significant differences between the intercanine widths of Class II division 1 and Class II division 2 malocclusions.

$\mathrm{H}_{\mathrm{a}}=$ There were significant differences between intercanine widths of class II division 1 and Class II division 2 malocclusions.

\section{RESULT}

Based on this study, the average intercanine widths of the maxilla in class II division 1 malocclusion were narrower than class II division 2 , and the average intercanine widths of the 
Table 1. The result of average intercanine width measurement

\begin{tabular}{ccc}
\hline Average intercanine width & Class II div. 1 & Class II div. 2 \\
\hline maxilla & $33.99 \mathrm{~mm}$ & $34.77 \mathrm{~mm}$ \\
mandibulla & $26.33 \mathrm{~mm}$ & $25.37 \mathrm{~mm}$ \\
\hline
\end{tabular}

Table 2. Comparison of maxilla intercanine width between Angle Class II division 1 and Class II division 2 malocclusions

\begin{tabular}{cc}
\hline Maxilla Intercanine width & Class II div. 1 vs Class II div. 2 \\
\hline N & 67 \\
T & -1.113 \\
Df & 65 \\
P value & 0.270 \\
Result & $\mathrm{H}_{0}$ Accepted \\
\hline
\end{tabular}

Table 3. Comparison of mandibula intercanine width between Angle Class II division 1 and Class II division 2 malocclusions

\begin{tabular}{cc}
\hline $\begin{array}{c}\text { Mandibula Intercanine } \\
\text { width }\end{array}$ & Class II div. 1 vs Class II div. 2 \\
\hline N & 67 \\
T & 1.608 \\
Df & 65 \\
P value & 0.113 \\
Result & $\mathrm{H}_{0}$ Accepted \\
\hline
\end{tabular}

mandible in class II division 1 were larger than class II division 2 (Tab. 1). The result of this study showed no statistical significant differences in the intercanine widths between Angle Class II division 1 and Class II division 2 malocclusions.

\section{DISCUSSION}

Based on this study, the average intercanine widths of the maxilla in the Angle Class II division 1 malocclusion were narrower than that of the class II division 2, whereas the average mandibular intercanine widths in the Angle Class II division 1 maloclusions were larger than Class II division 2. Another study also used the same method to determine intercaninewidthwasdonebyPateletal. ${ }^{8}$

In that study, the average width of the maxillary and the mandibulary intercanines in Angle Class II division 1 were narrower than those in class II division 2. It showed that the differences between the average of the mandibular intercanine widths in the Angle Class II division 1 when compared to class II division 2 in this study were in accordance to the research of Patel et al. ${ }^{8}$
The results of another study performed by Musthaq et al. ${ }^{10}$ showed that the average width of the maxillary intercanine of Angle class II division 1 malocclusions was narrower than that of class II division 2 and the average width of the mandibular intercanine of Angle Class II division 1 was larger than class II division 2 . The difference showed that the width of intercanine varied in each person. The differences were influenced by several factors such as genetics, race, gender and environments. Cassidy et al. ${ }^{11}$ performed previous research that linked genetic and sex to factors affecting the intercanine width. The results showed that the intercanine widths in males were significantly greater than in females. Other studies by Carillo et al..$^{12}$ demonstrated that race factors had effects on the intercanine widths. It showed that the intercanine widths in Mazahua adolescents were greater than in Mestizo. ${ }^{12}$

Based on statistical test, comparative hypothesis test results in this study showed no significant differences in intercanine widths between Class II division 1 and Class II division 2. (Shown in Table 2 and 3). The same results were also obtained in a previous study by Uysal et al. ${ }^{13}$ Based on statistical analysis of independent t-test showed no significant difference in intercanine width between class II division 1 and Class II division 2, although there were differences in avarage values of each variable when compared.

The results of this study proved that the differences in dental arch forms in class II division 1 malocclusions which generally had ' $V$ ' shaped arches and class II division 2 with the ' $U$ ' form had little effects on intercanine widths.

\section{CONCLUSION}

There was no differences in intercanine width in between Angle class II division 1 and division 2 malocclusions.

\section{REFERENCES}

1. Zhou Z, Liu F, Shen S, Shang L, Shang L, Wang $X$. Prevalence of and factors affecting malocclusion in primary dentition among children in Xi'an, China. China: BMC Oral Health. 2016.

2. Dewi O. Analisis hubungan maloklusi dengan kualitas hidup pada remaja SMU Kota Medan 
Tahun 2007. Medan: Fakultas Kedokteran Gigi Universitas Sumatera Utara. 2008. p. 3,15.

3. Singh VP, Sharma A. Epidemiology of malocclusion and assesment of orthodontic treatment need for Nepalese Children. Int Scholarly Res Notices 2014. p. 12-5.

4. Bishara SE. Class II malocclusions: diagnostic and clinical considerations with and without treatment. Seminars in Orthodontics 2006:12(1):11-24.

5. Bughaigis, Iman and Karanth, Divakar. 2013. The prevalence of malocclusion in Urban Libyan schoolchildren. J Orthod Scie 2013;2:1-6.

6. Coskuner HG, Ciger S. Three-dimensional assessment of the temporomandibular joint and mandibular dimensions after early correction of the maxillary arch form in patient with Class II division 1 or division 2 malocclusion. Korean J Orthod 2015:45(3):121-9.

7. Qamar CR, Riaz M, Awan SM. Dental arch width in Class 1 normal occlusion and Class II division 1 malocclusion. Pakistan Oral Dent J 2012:32(2):241-4.

8. Patel D, Mehta F, Patel N, Mehta N, Trivedi I, Mehta A. Evaluation of arch among Class I normal occlusion, Class II division 1, Class II division 2, and Class III malocclusion in Indian Population. Contemp Clin Dent 2015;6(suppl 1):202-9.

9. Staley RN, Reske NT. Essentials of orthodontics diagnosis and treatment. Oxford: Wiley-Blackwell Ltd.; 2011.

10. Mushtaq N, Tajik I, Basheer S, Shakeel S. Intercanine and intermolar width in Angle Class I, II, and III malocclusions. Pakistan Oral \& Dent J 2014:34(1):83-7.

11. Cassidy KM, Harris EF, Tolley EA, Keim RG. Genetic influence on dental arch form in orthodontic patient. Angle Orthod 1998:68(5):44554.

12. Carillo EL, Gonzales-Peres JC, Kubodera-Ito T, Montiel-Bastida KM, Esquivel-Pereyra GI. Dental arch morphology of Mazahua and Mestizo teenagers from Central Mexico. Braz J Oral Sci 2009;8(2):92-6.

13. Uysal T, Memili B, Usumez S, Sari Z. Dental and alveolar arch width in normal occlusion, Class II division 1 and Class II division 2. EH Angle Education and Research Foundation, Inc. 2005:75(6):941-7. 